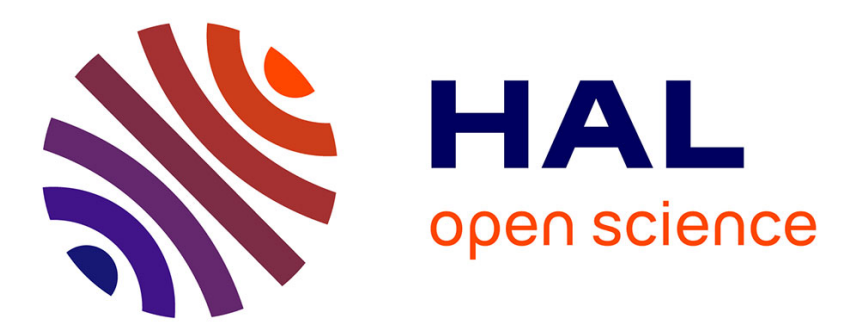

\title{
Monitoring discharge in a tidal river using water level observations: Application to the Saigon River, Vietnam
} \author{
B. Camenen, N. Gratiot, J.-A. Cohard, F. Gard, V.Q. Tran, A.-T. Nguyen,
} Guillaume Dramais, T. van Emmerik, J. Némery

\section{- To cite this version:}

B. Camenen, N. Gratiot, J.-A. Cohard, F. Gard, V.Q. Tran, et al.. Monitoring discharge in a tidal river using water level observations: Application to the Saigon River, Vietnam. Science of the Total Environment, 2021, 761, pp.1-12. 10.1016/j.scitotenv.2020.143195 . hal-03118389

\author{
HAL Id: hal-03118389 \\ https://hal.science/hal-03118389
}

Submitted on 22 Jan 2021

HAL is a multi-disciplinary open access archive for the deposit and dissemination of scientific research documents, whether they are published or not. The documents may come from teaching and research institutions in France or abroad, or from public or private research centers.
L'archive ouverte pluridisciplinaire HAL, est destinée au dépôt et à la diffusion de documents scientifiques de niveau recherche, publiés ou non, émanant des établissements d'enseignement et de recherche français ou étrangers, des laboratoires publics ou privés. 


\section{Monitoring discharge in a tidal river using water level observations: application to the Saigon River, Vietnam}

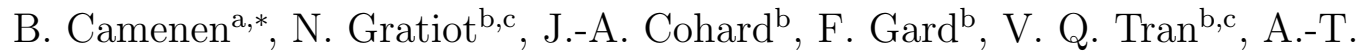
Nguyen $^{\mathrm{b}, \mathrm{c}}$, G. Dramais ${ }^{\mathrm{a}}$, T. van Emmerik ${ }^{\mathrm{d}}$, J. Némery ${ }^{\mathrm{b}, \mathrm{c}}$

${ }^{a}$ Inrae, UR RiverLy, centre de Lyon-Grenoble, Villeurbanne, France

${ }^{b}$ CARE, IRD, Ho-Chi-Minh-City, Vietnam

${ }^{c} I G E$, Univ. Grenoble Alpes / CNRS / IRD / Grenoble INP, Grenoble, France

${ }^{d} H Q W M$, Univ. Wageningen, Wageningen, The Netherlands

\section{Abstract}

The hydrological dynamics of the Saigon River is ruled by a complex combination of factors, which need to be disentangled to prevent and limit risks of flooding and salt intrusion. In particular, the Saigon water discharge is highly influenced by tidal cycles with a relatively low net discharge. This study proposes a low-cost technique to estimate river discharge at high frequency (every 10 minutes in this study). It is based on a stage-fall-discharge (SFD) rating curve adapted from the general Manning Strickler law, and calibrated thanks to two ADCP campaigns. Two pressure sensors were placed at different locations of the river in September 2016: one at the centre of Ho Chi Minh City and one in Phu Cuong, $40 \mathrm{~km}$ upstream approximately. The instantaneous water discharge data were used to evaluate the net residual discharge and to highlight seasonal and inter-annual trends. Both water

\footnotetext{
${ }^{*}$ Corresponding author, benoit.camenen@inrae.fr
} 
level and water discharge show a seasonal behaviour. Rainfall, including during the Usagi typhoon that hit the megalopolis in November 2018, has no clear and direct impact on water level and water discharge due to the delta flat morphology and complex response between main channel and side channel network and ground water in this estuarine system under tidal influence. However, we found some evidences of interactions between precipitation, groundwater, the river network and possibly coastal waters. This paper can be seen as a proof of concept to (1) present a low-cost discharge method that can be applied to other tidal rivers, and (2) demonstrate how the high-frequency discharge data obtained with this method can be used to evaluate discharge dynamics in tidal river systems.

Keywords: Saigon River, water level, water discharge, tidal river, flood, stage-fall-discharge rating curve.

\section{Introduction}

2 A good understanding of the hydrological cycle, and discharge in partic3 ular, in tidal rivers enables reliable forecasting and decision making by re4 searchers and policy makers. Some priorities are generally put on the protec5 tions against floods, saline intrusion and the dynamics of pollutants because 6 of the social, economic and political stakes they are linked to. Hydrological 7 cycles in Low Elevation Coastal (and deltaic) Zone (LECZ, 0-10 masl) differ 
8 a lot from their upstream environments due to the tidal influence (van Driel 9 et al., 2015). Although this is a strategic zone at the interface between land and ocean, physical and environmental data collected in this environment remain sparse because of inherent logistical difficulties due to the unsteadiness of the flow (Taniguchi et al., 2013). On one hand, the river water discharge is influenced by tidal dynamics, which modulate hydrodynamics at high and low frequency and can reshape the geomorphology, with feedback loops on hydrodynamics (Mao et al., 2004). On the other hand, estuarine and deltaic zones are highly influenced by peak fresh water discharges, which are themselves modulated by tidal asymmetry (Sassi and Hoitink, 2013).

In the floodplain of the Saigon River, which is part of the LECZ of the south of Vietnam, vulnerability could be assessed according to four factors (McGranahan et al., 2007; van Driel et al., 2015) : (i) Relative Sea Level Rise (RSLR) due to climate change and natural and anthropogenic subsidence; (ii) Wetland ecological threat; (iii) Population pressure: and (iv) Delta governance (adaptivity, participation, fragmentation). The Saigon River flows through Ho Chi Minh City (HCMC), a highly populated area, where population density can reach up to 30,000 inhabitants $/ \mathrm{km}^{2}$ (Nguyen et al., 2019).

${ }_{26}$ The unprecedented growth of HCMC induces pressure on the environment 27 and especially water resources (Van Leeuwen et al., 2016).

28 A major issue in such regions is to measure the instantaneous discharge 
${ }_{29}$ for a tidal river and to evaluate the residual discharge of the tide-affected

44 cessfully in some tidal rivers such as the Sacramento River, California (Ruhl

48 ADP (Acoustic Doppler Profiler) current meter was deployed on the Tan49 shui River, Taiwan (Chen et al., 2012b) or fixed ADCPs (Acoustic Doppler 
Current Profiler) on the Yangtze River at Xuliujing, China (Zhao et al., 2016; Mei et al., 2019). These methods remain however expensive (around $30 \mathrm{k} €$ excluding structural works and maintenance) and difficult to display in an urban place due to risk of vandalism.

In a recent work, Camenen et al. (2017) proposed to apply a stage-falldischarge rating curve to estimate instantaneous discharges in tidal rivers. Such simple model can be calibrated using intense discharge campaigns achieved over a full tide cycle, which are easily available nowadays thanks to the ADCP technology. The first application of the method was based on field measurements made on the Saigon River in September 2016 and was particularly successful (Camenen et al., 2017). It presented some limitations for a very asymetric tidal wave (close to a tidal bore), which is not the case for the Saigon River.

63 In this paper, this simple low-cost water level-based discharge monitoring is applied the Saigon River for a two-year period. A calibration and validation of the method are first presented. The monitoring of two hydrological seasons from January 2017 to Dec 2019 is then discussed. Results obtained allow for examining and discussing two specific aspects : first, what is the hydrological pattern of the Saigon River at different time scales, from the event scale to 9 years, and how is it influenced by the sea level ; second, how much the rainfall regime is directly influencing the Saigon River dynamics, in particular, how 
71 does the river react to extreme events?

\section{Material and methods}

\subsection{Study site}

The Saigon River is located in the South of Vietnam, in a low elevation coastal zone, i.e. between 0 and $10 \mathrm{~m}$ above mean sea level (MSL, Figure 1). The Saigon River takes its source in Cambodia and is $225 \mathrm{~km}$ long. Its catchment area has a surface of $4717 \mathrm{~km}^{2}$ (Nguyen et al., 2019). The Saigon River is actually a complex river system, subject to several human and environmental interactions, including many canals while it crosses Ho Chi Minh City (HCMC) megalopolis, before flowing into the Dong Nai River and the coastal waters. Upstream the megalopolis, the river is regulated by the Dau Tieng dam, which was built during the 1980's, in order to mitigate saline intrusion and secure the fresh water supply uptake station of HCMC. The situation of HCMC is all the more critical as $65 \%$ of the city is located at an altitude of $1.5 \mathrm{~m}$ above MSL (Scussolini et al., 2017; Vachaud et al., 2019)

The flow of the Saigon River is predominantly driven by tidal currents, which affects both the water level and water discharge, with regular exfiltration of water in some urban districts during high spring tides. Over the year, precipitation follow two contrasted seasons: the dry season, usually ex- 


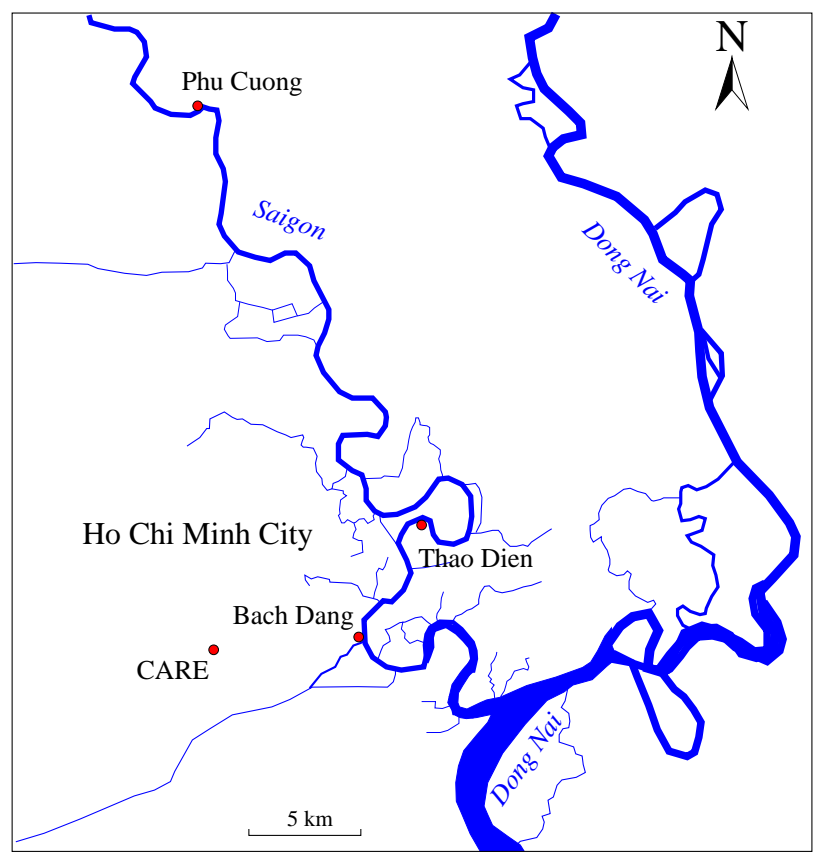

(a)

(b)

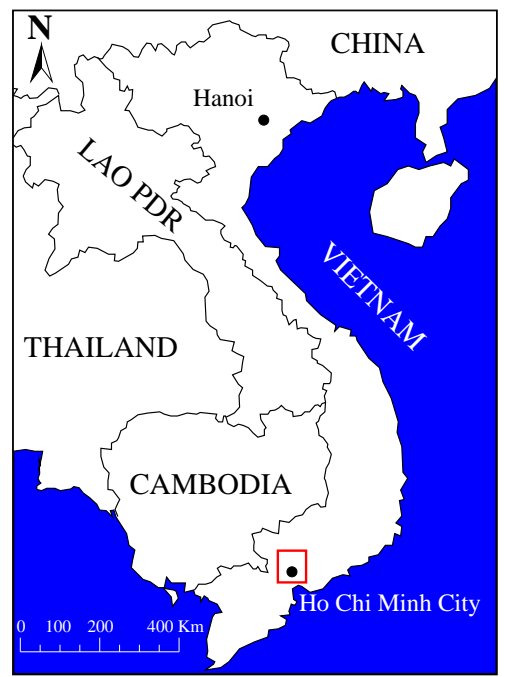

Figure 1: Location of the study site: the low elevation coastal zone of the Saigon River system, including the Saigon and Dong Nai rivers and Ho Chi Minh City (red points correspond to the position of pressure gauges).

tending from November to April and the wet season from May to October, which gathers about $80 \%$ of the total rain (Nguyen et al., 2019). Rain event can be severe and precipitation record can locally exceed $300 \mathrm{~mm} /$ day, even

${ }_{97}$ in rainfall which caused flooding, material and human damages reported in 
several newspapers.

\subsection{Water discharge estimation}

The instantaneous water discharge was estimated by applying a stage-falldischarge (SFD) rating curve adapted from the general Manning-Strickler law, previously tested and validated by Camenen et al. (2017). This model is based on the assumption of a pseudo-uniform flow and a prismatic section, which is valid for a low slope river with slowly varying water depth. Considering an almost constant flow between two water level measures, the Manning-Strickler equation can be applied :

$$
Q=K A_{w} R_{h}^{2 / 3} \sqrt{S}
$$

with $Q$ the water discharge $\left[\mathrm{m}^{3} / s\right], K$ the Manning-Strickler coefficient $\left[\mathrm{m}^{1 / 3} / s\right]$, $R_{h}=A_{w} / P_{w}$ the hydraulic radius $[\mathrm{m}], A_{w}$ the wet section $\left[\mathrm{m}^{2}\right], P_{w}$ the wet perimeter [m], and $S$ the energy slope [-] assumed equal to the water slope. Another assumption made here is that the river section and reach are stable with no significant bed changes. It was verified by comparing the different bathymetries from both ADCP campaigns.

Two hydrological stations are needed to evaluate the hydraulic slope of the river: the water level $z_{u p}$ and $z_{d n}$ were measured at Phu Cuong (upstream station) and Bach Dang then Thao Dien stations (downstream stations), which are named "PC", "BD", and "TD" hereafter (see Fig. 1a). Distance 
between stations is around $L=42 \mathrm{~km}(\mathrm{PC}-\mathrm{BD})$ and $L=35 \mathrm{~km}$ (PC-TD), which is sufficient to have a significant difference in altitude and to estimate slope with a good resolution for this low slope system. Due to tides and flow oscillation, the slope oscillates between positive and negative values. Also, the slope in Equation (1) $\left(S=\left(z_{u p}-z_{d n}\right) / L\right)$ does not correspond to the local slope at the point in which the discharge is evaluated, i.e. at Phu Cuong (PC). Indeed, because of the distance between the two stations, the flow discharge is slightly different at the two stations. However, this spatial offset can be translated as a lag time $\Delta t$. As a consequence, the discharge estimation at $\mathrm{PC}$ can be written :

$$
Q(t)=K A_{w}\left(z_{u p}(t)\right) R_{h}\left(z_{u p}(t)\right)^{2 / 3} \sqrt{|S(t+\Delta t)|} \frac{S(t+\Delta t)}{|S(t+\Delta t)|}
$$

By specifying the river cross-section at PC (assuming it is relevant for the whole reach), one can easily evaluate $A_{w}$ and $R_{h}$ as a function of the water level $z_{u p}$. In Equation (2), two parameters need to be calibrated :

- $K$, the Strickler coefficient of the river reach supposed homogeneous between $\mathrm{PC}$ and $\mathrm{BD}$,

- $\Delta t$, a priori negative since the tide progresses from downstream to upstream.

The Strickler coefficient could vary depending on the discharge due to additional head losses at low flows (emergence of sills) or at high flows (flood-plain 
interaction). Nevertheless, such cases were not observed for the specific case of the Saigon River.

\subsection{Water level measurement}

To apply Equation (2), CTD DivER sensors were installed at PC and BD stations in September 2016, as reported in Figure 1. They measure pressure, conductivity and temperature every 10 minutes. Conductivity and temperature were considered as interesting proxy to interpret data series and were used to operate the post processing, but were not used directly in this study. PC sensor was immersed in the river bank of the Saigon River, close to Phu Cuong city, TD sensor was immersed in the heart of the megalopolis of Ho Chi Minh City, in Thao Dien district. Both sensors were downloaded at a bimonthly basis. Due to logistical constraints, significant risks of theft and of mechanical deterioration, TD station was displaced twice with a corresponding adjustment of parameters in Equation (2) $(L$ and $\Delta t)$. The sensor was initially installed in Bach Dang, in the city centre in September 2016. It was moved to Boat House (BH), $8.5 \mathrm{~km}$ upstream of the Bach Dang point, from January 2017 to the 8th of March 2017. Then, since 15th March 2017, the sensor is located in Thao Dien Village (TD). Distance between those two last sites is only $0.9 \mathrm{~km}$. To compensate water level measurements from atmospheric pressure fluctuations, a barometer was installed at the CARE 
center (Ho Chi Minh University of Technology, see Figure 1).

Some drifts of the water level measurements were observed due to fine deposit accumulation leading to over-pressure. Water levels at PC and TD were thus corrected based on monthly campaigns made by Sub Institute of Hydrometeorology and Climate Change (SIHYMECC, also named CEM hereafter for Center of Environmental Monitoring) of Ho Chi Minh City. During these campaigns, water levels were measured every hour for three days at the staff gauge. In Figure 2, one can observed a very good agreement between CTD Diver data and SIHYMECC data (the water level $H$ corresponds the the difference between the water surface level and a reference level of the station).

(a)

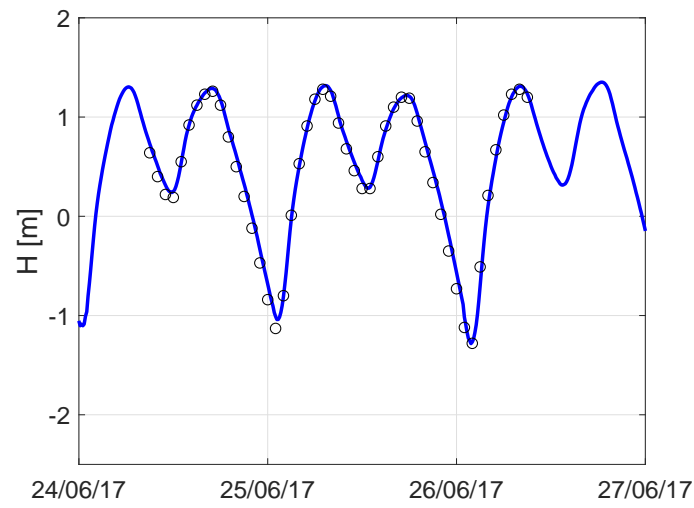

(b)

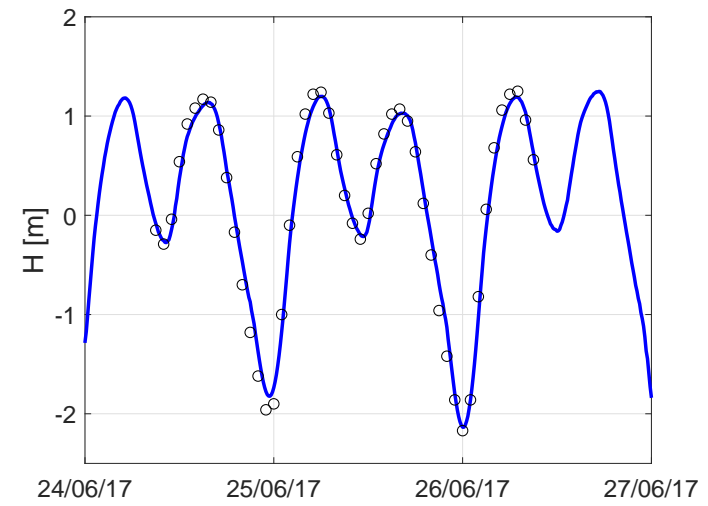

Figure 2: Comparison between water levels $H$ measured at PC (a) and TD (b) stations and water levels measured by the SIHYMECC at the staff gauges for the selected period between 24th to 27th of June 2017. 


\subsection{Residual discharge}

In order to study the net water discharge in the Saigon River and evaluate the hydrological cycle, the instantaneous water discharge needs to be averaged over four tide periods $\left(T_{\text {tide }}=12.4\right.$ hours $)$ to filter the 1 st order semi-diurnal tidal signal from the data-series. As a consequence, $Q_{n}\left(t_{0}\right)=$ $\int_{t_{0}-2 T_{\text {tide }}}^{t_{0}+2 T_{\text {tide }}} Q(t) d t$. In the same way, the tidal averaged water level can be obtained such as $z_{t a}\left(t_{0}\right)=\int_{t_{0}-2 T_{\text {tide }}}^{t_{0}+2 T_{\text {tide }}} z(t) d t$. The acquisition of data at high frequency (every 10 minutes) and over a longer period (two hydrological seasons) is a prerequisite to such evaluation.

\section{Calibration and validation of the SFD rating curve}

\subsection{Calibration of the model using ADCP campaigns}

Two Acoustic Doppler Current Profiler (ADCP) campaigns have been led in September 2016 and March 2017 with a Rio Grande 600 kHz (Dinehart and Burau, 2005). During 24 hours and for every hour, one gauging, i.e. three transects, was realized at PC with a boat and a georeferenced ADCP mounted on it. ADCP campaigns were used to calibrate the water discharge estimation, calculated with Equation (2) (Camenen et al., 2017). $K$ and $\Delta t$ were calibrated such as the modelled discharge fit to observed data (see also appendix Appendix A.1). Also, since it is very difficult to evaluate the exact vertical reference level of each station, these campaigns were used to 
optimize the measured difference $z_{u p}-z_{d n}$ using an additional parameter $\Delta z$ (i.e. $\left.z_{u p}-z_{d n}=\left(z_{u p}-z_{d n}\right)_{\text {measured }}+\Delta z\right)$

To ensure the robustness of the hydraulic model, calibration were realized during both wet (September 2016) and dry (March 2017) seasons. These ADCP campaigns were also used to determine the river cross-section characteristics, to calculate $A_{w}$ and $R_{h}$ as a function of water level. Error in ADCP measurements were evaluated at $10 \%$ using a minimum error value of $100 \mathrm{~m}^{3} / \mathrm{s}$ since the conditions were adverse (Le Coz et al., 2016). We found the best results using a Manning-Strickler coefficient $K=26 \mathrm{~m}^{1 / 3} / \mathrm{s}$ and $\Delta t=-2.0$ hours (see Appendix Appendix A.1). Results are presented in Fig. 3. Very good results can be observed for the September 2016 campaign. Some slight error may be observed at the end of the first flow peak (Fig. 3a, at around $21 \mathrm{~h}$, local time) but it is due to a pressure gauge outside water. For the 2017 campaign, results are not as accurate but still in good agreement with data. The clear asymmetric semi-diurnal tidal signal for this specific day may explain some of the differences (Camenen et al., 2017).

\subsection{Validation of the model using other discharge estimations}

The monthly campaigns made by SIHYMECC also include some discharge estimation every hour for $48 \mathrm{~h}$. They applied the velocity index method by measuring the water level and the depth-averaged velocity $\overline{u_{\text {index }}}$ 
(a)

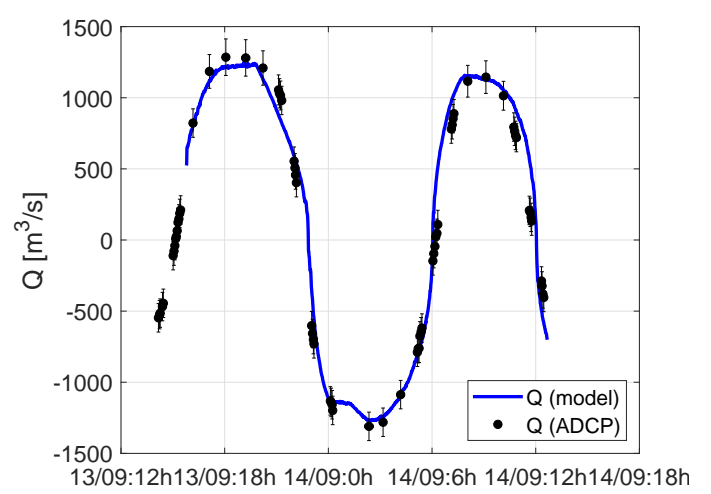

(b)

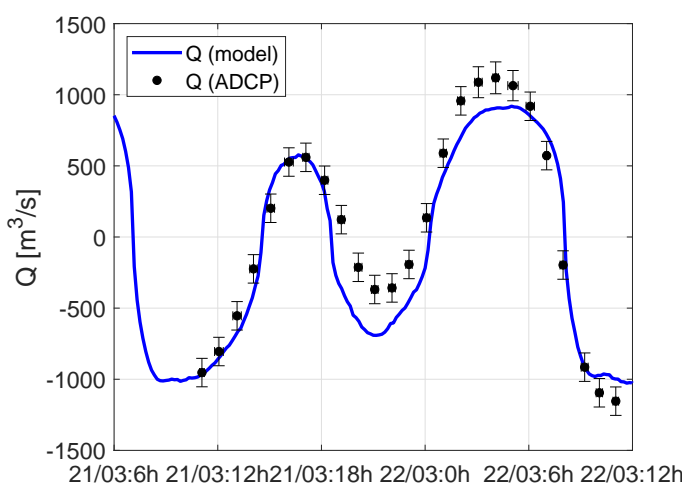

Figure 3: Water discharge $Q$ comparison between model results and ADCP measurement campaigns in September 2016 (a) and March 2017 (b).

207

at one location $y_{\text {index }}$ (Chen et al., 2012b) :

$$
Q=\alpha_{\text {index }} \overline{u_{\text {index }}} A_{w}
$$

with $\alpha_{\text {index }}=0.8$ a calibration coefficient, $\alpha_{\text {index }}=U / \overline{u_{\text {index }}}$ where $U=Q / A_{w}$ the section-averaged velocity. Again, since conditions are adverse, we roughly estimated the error from this method equal to $15 \%$ plus a minimum error of $150 \mathrm{~m}^{3} / \mathrm{s}$ based on Ruhl and Simpson (2006).

The corresponding water discharge estimated from Equation (2) are in good agreement with data from SIHYMECC (Fig. 4). The model tends to yield smaller peak values for the inward discharge (negative), even if this trend is not observed for all tidal cycles. This tendency is more pronounced for the 2018 data (Fig. 4b). This could be the consequence of either a varying flow repartition throughout the river section during the ebb and flow 
(a)

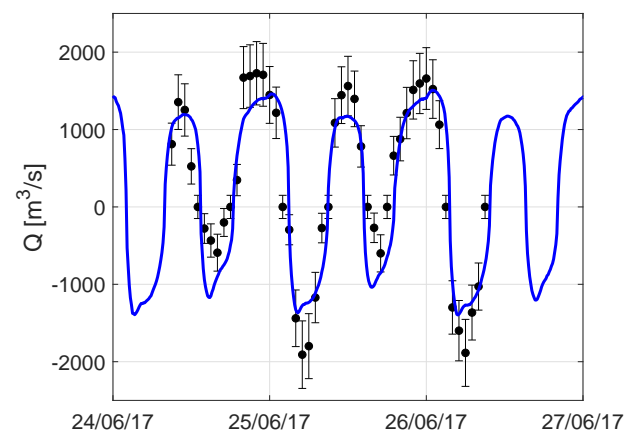

(b)

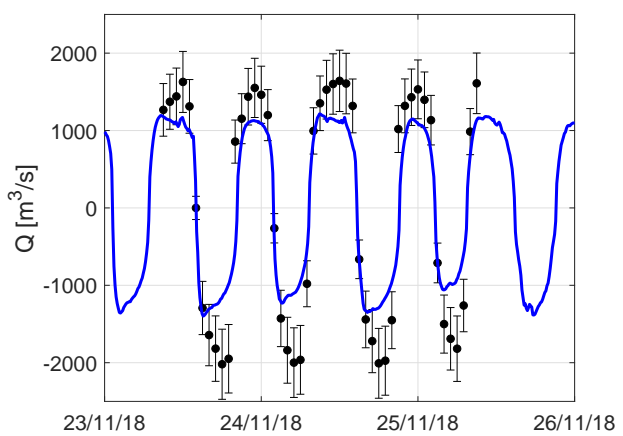

Figure 4: Water discharge $Q$ estimated at PC (blue line) in comparison to SIHYMECC data for two contrasting hydrological periods in June 2017 (a) and in November 2018 (b).

\section{A two-year monitoring of the Saigon River}

\subsection{Water levels}

The water level time series, which covers two hydrological years, from January 2017 to December 2018 are reported in Figure 5a. For both stations, the reference level is the one of the staff gauge, which explains the existence of some negative values.

In each panel, one can see that the tidal signal clearly predominates with a strong semi-diurnal harmonic. The cyclicity is particularly emphasized through the examination of a zoomed period in September 2018 (Figure 

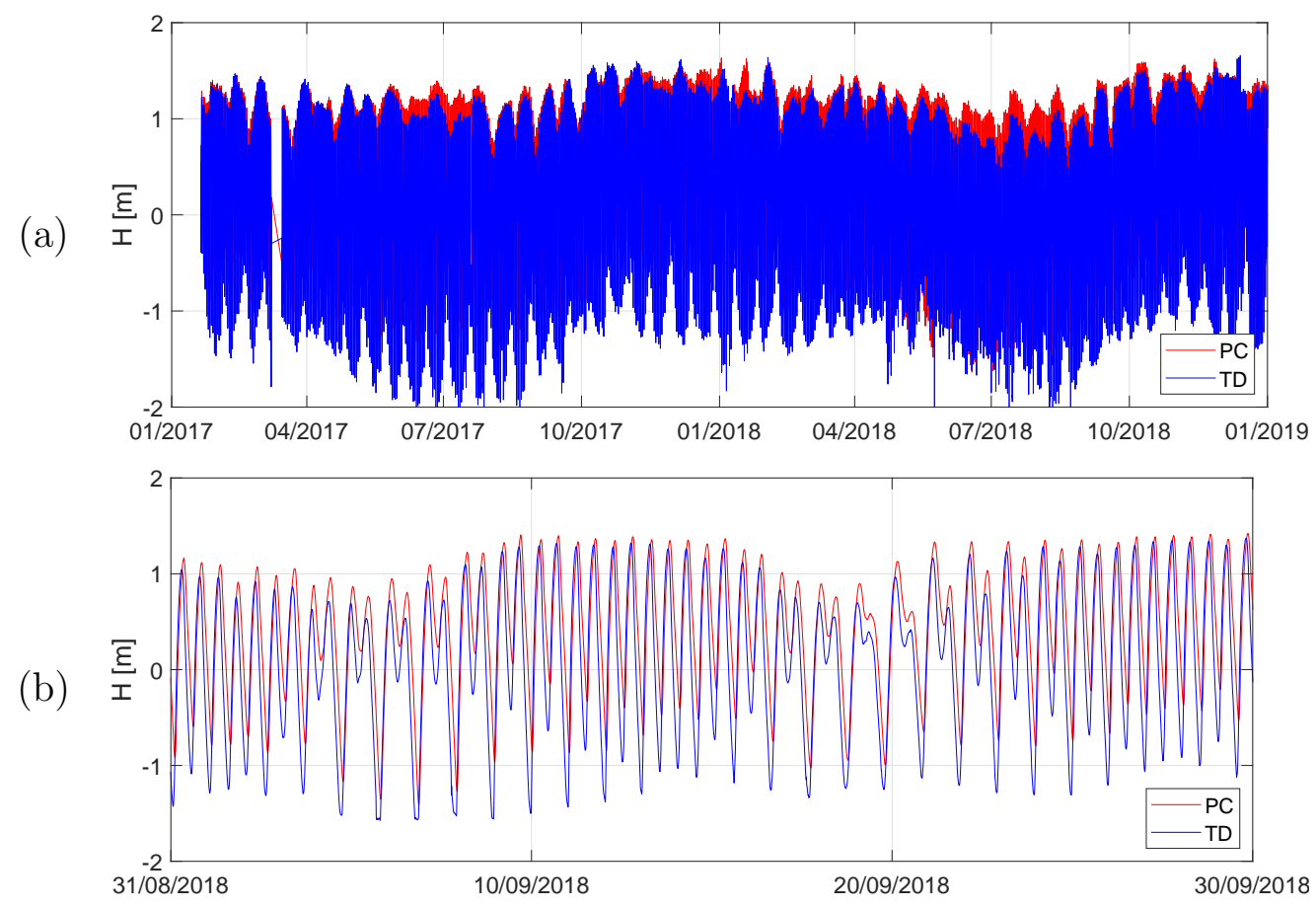

Figure 5: Two-year water level time series measured at PC and TD (a) with a zoom in September 2018 (b).

5b). The cyclicity is evidenced on both PC and TD stations, who present synchronous fluctuations, with a time laps of about 1 hour and 10 minutes, which corresponds to the duration of tide wave propagation between the two stations. The tidal magnitude is smaller at PC station (by 17\%) than at TD station, which is physically consistent with quadratic friction dissipation: the further upstream the station is, the less it is influenced by tidal waves. Tidal range was measured to oscillate between $-2.00 \mathrm{~m}$ and $1.50 \mathrm{~m}$ at both TD and PC stations.

A first glimpse of seasonality can be observed in the two-year time-series. 
One can observe lower water levels in the rainy season (May to September) and higher values in the dry season (November to March). Semi-diurnal tidal forcing clearly prevails on the Saigon River. As illustrated in Figures 2 and 5, the 14-days cycle presented both symmetric and asymmetric tides; a pattern which is particularly well developed in the estuaries located in the south of Vietnam (Chen et al., 2012b).

\subsection{Continuous discharge estimation}

By applying Equation (2), one can easily calculate the discharge at PC using water levels from both PC and TD stations. Water discharge is dominated by tidal semi-diurnal harmonics, as for water level data-series (Figure 6). Instantaneous discharge ranged from -2000 to $2000 \mathrm{~m}^{3} / \mathrm{s}$. The oscillation of the magnitude of tides, between spring and neap tides, is also wellidentified (Figure 6b). Maxima appears at every syzygy between the sun, the moon and the earth. Overall, the analysis of instantaneous water discharge highlighted the predominant forcing of tides on any other forcing, despite contrasted and well-marked dry and rainy seasons.

\subsection{Residual discharge}

All data from the SIHYMECC field campaigns (which correspond to a $48 \mathrm{~h}$ experiment $\approx 4 T_{\text {tide }}$ ) were compared to the proposed model (Figure $7 \mathrm{a}$ ). As expected, since the model yields smaller amplitudes (see Figure 4), one 

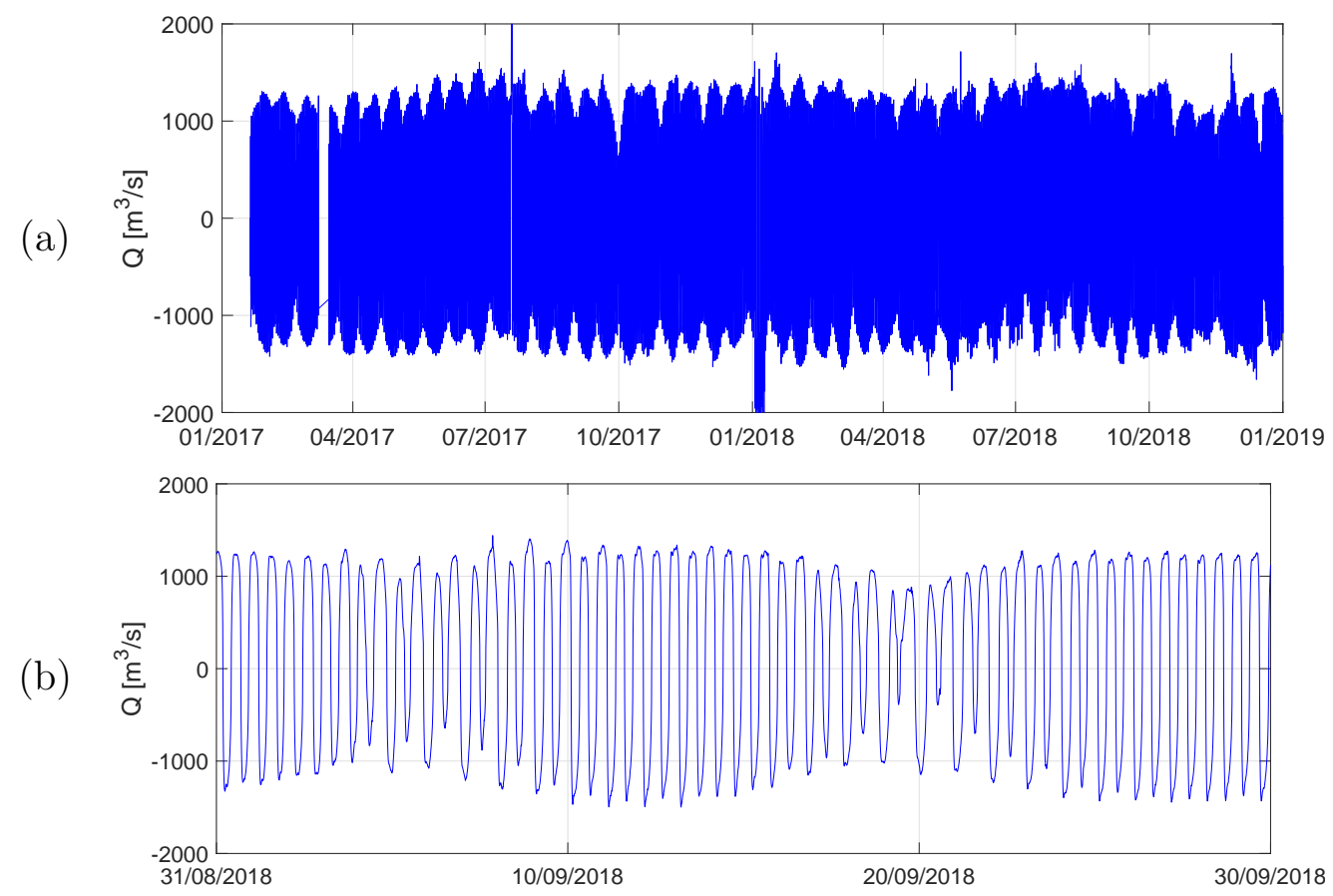

Figure 6: Two-year water discharge time-series (a) with a zoom in September 2018 (b) at Phu Cuong (PC).

generally finds a good correlation but with few outliers, predominantly above the 1:1 line for negative discharge and bellow the 1:1 line for positive discharge (i.e. $\left.\left|Q_{\text {model }}\right| \operatorname{sim}|Q(C E M)|\right)$. One should note also the many zero values for the SIHYMECC (CEM) data, which may be the consequence of a human bias (while reading the staff gauge) and partly explains uncertainties in experimental data and some of the scatter in the model response. A comparison of the net water discharge measured by the SIHYMECC and modelled by our group is reported in Figure 7b for the 18 SIHYMECC campaigns available. One can realize the order of magnitude of difference between maximum in- 
stantaneous discharges and net discharges, which corresponds to the red box in Figure 7a. Despite the existence of few outliers, modelled points for net water discharge are well correlated with the estimation from measured data. As expected, since the model yields smaller amplitudes, the net discharge estimations are generally smaller. The existence of outliers is not surprising looking at the sensitivity of such calculation while net discharge is one order of magnitude smaller than peak values (positive and negative). But surprisingly, while SIHYMECC estimations of the net discharge are always positive, the proposed model leads sometimes to negative values. Although difficult to explain, these negative values may results from a combination of factors, such a the asymmetrical tides and complex exchanges with groundwater and with the canal network. The regular occurrence of salt intrusions up to HCMC does confirm the possible occurrence of a net negative water discharge. Also, as discussed above, the model is very sensitive to a possible error in water level estimation a PC and BD, TD stations. Hence, for the net discharge, we evaluated the error equal to $20 \mathrm{~m}^{3} / \mathrm{s}$ per $\mathrm{cm}$ of error in the vertical axis (See Appendix Appendix A.3).

The net discharge time series over this two-year experiment is presented in Figure 8. Compared to monthly SIHYMECC campaigns, we observe more variability in the net discharge time-series. Some spikes are however not realistic and result from data gaps (January 2018, December 2019). 
(a)

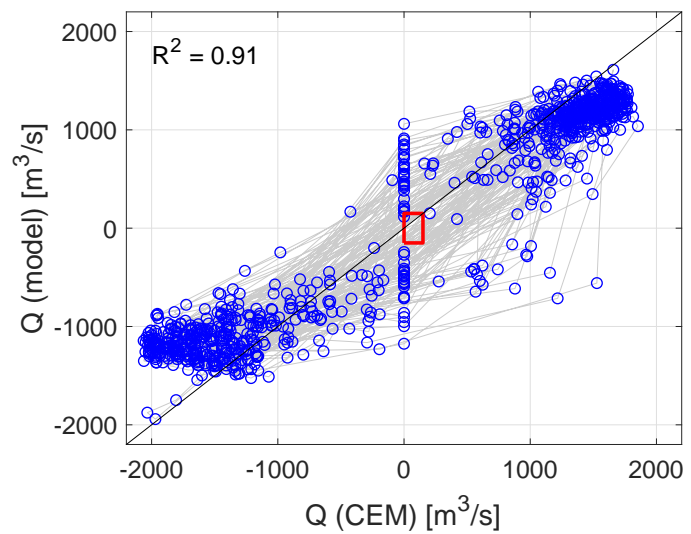

(b)

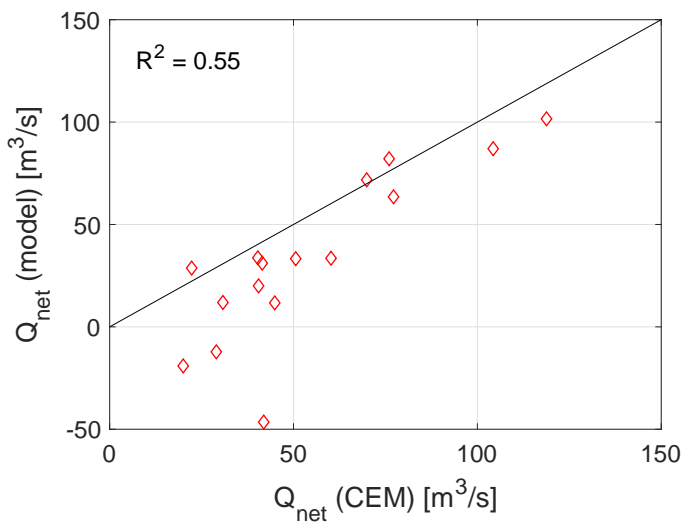

Figure 7: Comparison of the instantaneous (a) and net (b) discharges obtained by the SIHYMECC (CEM) and the proposed model for all 2017 and 2018 SIHYMECC campaigns.

The seasonality of precipitation in this tropical humid low lying area is expectedly a main driver of the annual hydrological cycle, but as shown previously, this driver is masked by the tidal forcing (Figure 8). The wet season is expectedly linked with a higher water discharge and a refill of the groundwater. At the opposite, the dry season is expectedly linked with a decrease of the net water discharge. This general pattern was broadly described by Nguyen et al. (2019), but needs to be detailed and should be understood on a physically based characterization of the main drivers. One can clearly observe the seasonality of net discharge with peak values during the wet season in Figure 8. In 2017, the peak net discharge reached $300 \mathrm{~m}^{3} / \mathrm{s}$ and lasted only for two months in the beginning of June and the end of 
July. In 2018, net discharges exceeded $200 \mathrm{~m}^{3} / \mathrm{s}$ from June to August with maximum values up to $400 \mathrm{~m}^{3} / \mathrm{s}$. It then decreased before a second peak was reached in early October. Flood extended for more than four months, leading to one of the most humid year of the decade (Fig. 8 and Fig. 10).

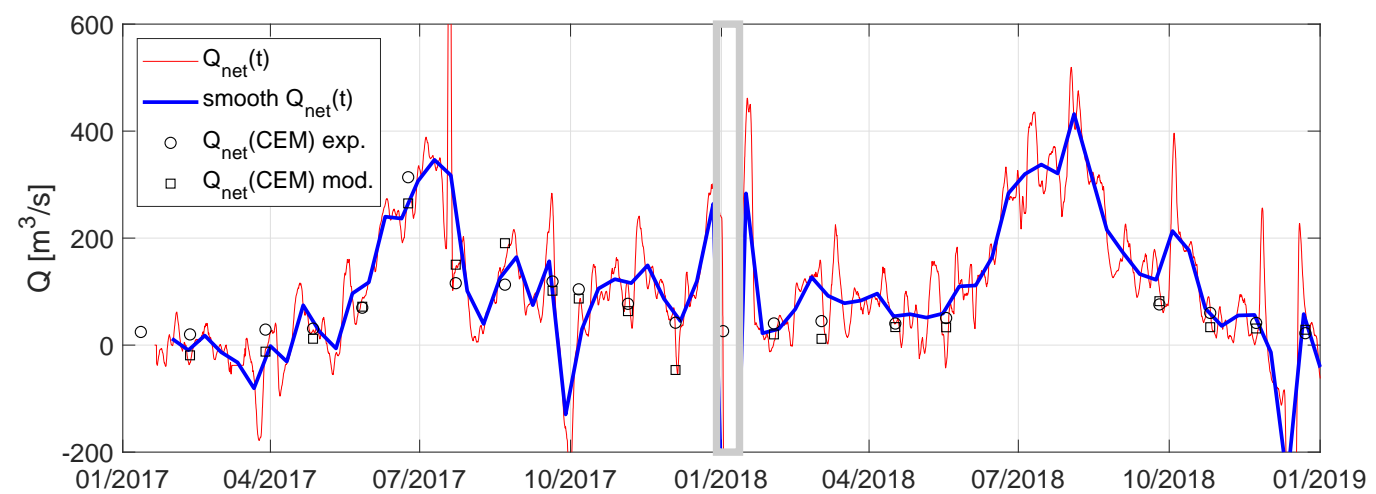

Figure 8: Net discharge $Q_{n e t}$ estimate for the January 2017 - December 2019 period (full lines correspond to the model results while symbols correspond to values for the SIHYMECC campaigns using their own estimations -exp.- or using the model -mod.-; the grey line delimits a period of missing data at PC).

Monthly cumulated precipitation, tide-averaged water level along the Saigon and Dong Nai rivers and monthly averaged net-discharge are presented in Figure 9 for the 2017 and 2018 periods. 2017 and 2018 rainy seasons are well-marked, with an increase in precipitation from June to October. In 2018, precipitations are particularly high and extended in October and November. The tide-averaged water level follows the rain pattern for both increasing and decreasing phases, with a shift of two to three months. 
Concerning the averaged water discharge, it was measured to fluctuate between -100 to $500 \mathrm{~m}^{3} / \mathrm{s}$ (no value is given for January 2018 since there was a too long gap in data), with a magnitude that was quite different for both hydrological years. In 2017, one can noticed that there exists an expected time lag between rain (first) and river discharge (few weeks later) but there is also some delayed and complex interactions with groundwater and/or water level. The rainy season, which started in May, was followed by a rise in the net water discharge only one month later (June) and then, by an increase of the tide-averaged water level few weeks later (July, August). Also, one observed a drop in net discharge in August and September, while precipitation remains high followed by a rise in net discharge while precipitation dropped. It seems there are strong exchanges of water with groundwater and/or floodplain with a possible recharge from the groundwater and/or floodplain in May, August and September and a restitution to the river in November and December. However, Van and Koontanakulvong (2018) estimated possible exchanges of water between the aquifer and the Saigon River of approximately $0.02 \mathrm{~m}^{3} / \mathrm{s}$ per $\mathrm{km}$, which appears negligible. Effects of the large drainage and canal system around the Saigon River (i.e. of the Saigon floodplain) may prevail here. Also, anthropogenic influences such as Dau Tieng dam management or water supply pumping may significantly affect the net Saigon river water discharge. In 2018, cumulated rain also led to an increase of the net water 
discharge, but the rise of the Saigon River discharge was much faster and almost correlated to precipitation, which lets presume that soil saturation was higher and led to a direct response of the river to precipitation. Even if rain initiated late in the season, as compared with year 2017 (May and June in 2018 instead of April and May in 2017), the shape and cumulative rain during the rainy season was quite comparable to 2017. The net water discharge responded similarly to 2017 in June 2018. However, in 2018 the response to precipitation is stronger with a monthly averaged net discharge above $400 \mathrm{~m}^{3} / \mathrm{s}$ in July and August. Surprisingly, in October and November, while precipitation is particularly high in fall and superimposed with the extreme typhoon event in late November, one can observe a decrease of the net discharge. Significant floods have been observed during this period; a large part of the water volume from precipitation may have been spread over the flood plain.

Looking at the tide-averaged water level (Figure 9b) measured at Phu Cuong (PC), Thao Dien (TD) or Phu An (PA), but also at Vam Sat (station located downstream on the Dong Nai River at approximately $20 \mathrm{~km}$ from the see shore), a clear annual fluctuation can be observed with high water levels from October to April. Such high values yield an averaged negative slope leading some counter-effects on the net discharge (see Appendix Appendix A.3). Interestingly, these fluctuations are not correlated to precipitations 
(a)

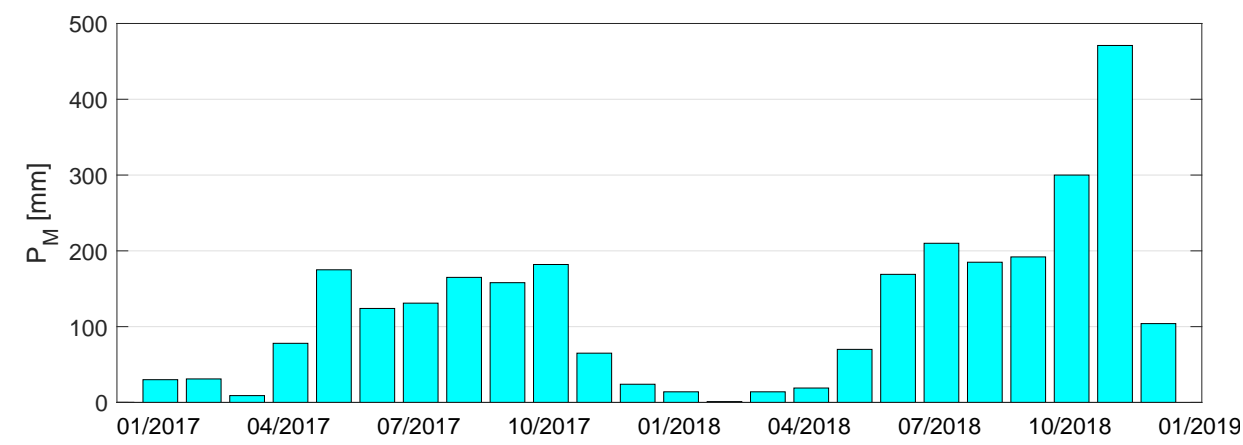

(b)

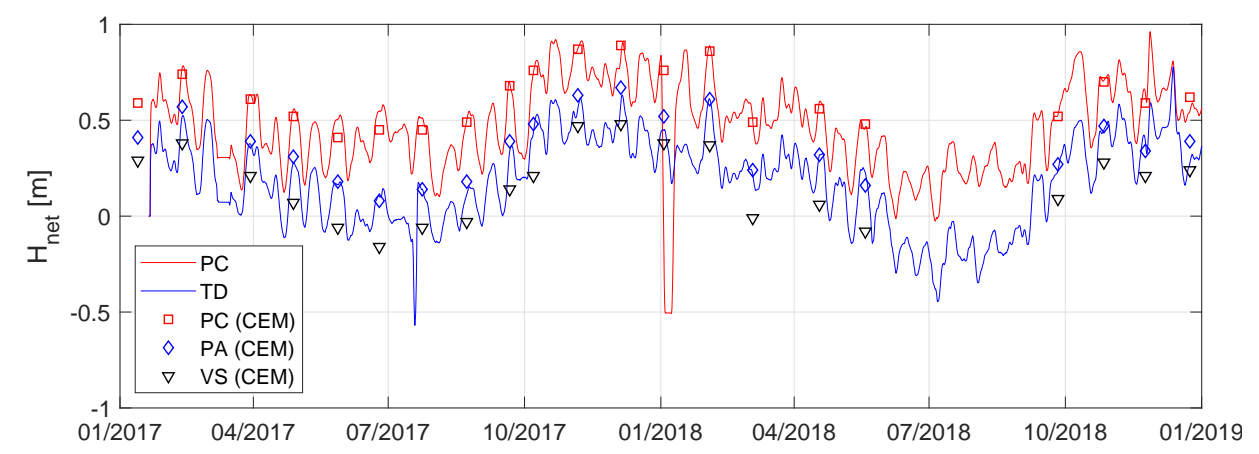

(c)

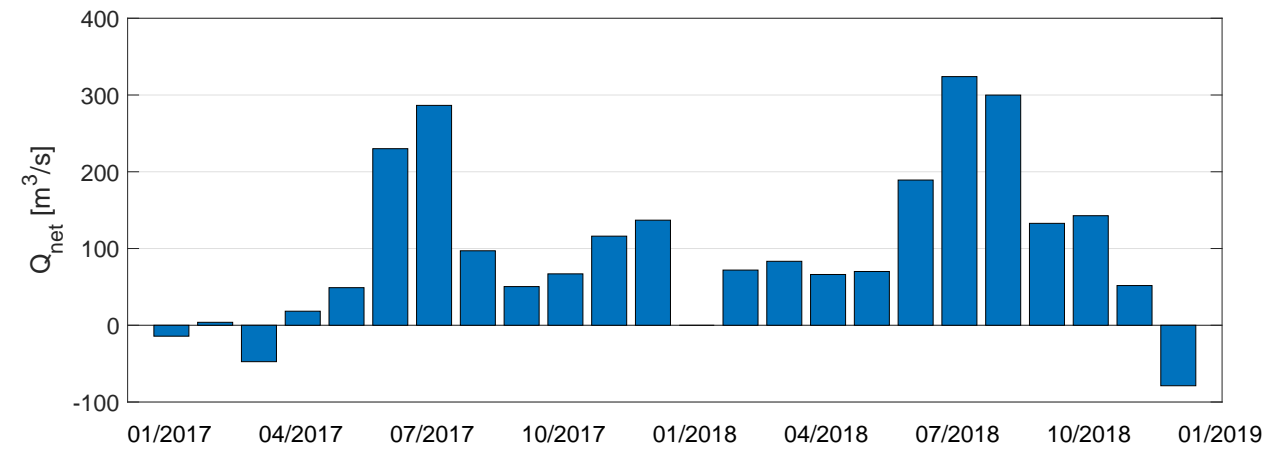

Figure 9: Monthly rainfall $P_{M}$ (a), tide-averaged water levels $H_{\text {net }}$ (b) and monthly net discharge $Q_{M, n e t}(\mathrm{c})$ for the January 2017 - December 2019 period. 


\subsection{Effects of long-term precipitation}

To get further in the analysis of the interaction between the Saigon River discharge and its surrounding floodplain, we examined a pluriannual monthly rainfall series (Figure 10). This series was associated with the severe Niño event in 2015-2016 (Thirumalai et al., 2017; Thi Ha et al., 2018). In Figure 10, one can observed a regular decrease of annual precipitation from 2009 to 2012, a minimum from 2013 to 2015 and an increase until 2019. The 2013-2015 period thus corresponded to a deficit of rain, which was evidenced by socio-political impacts described in newspapers, particularly during the dry season 2015-2016. This dry season was reported as the worst drought ever reported in 98 years of monitoring in the floodplains of Mekong and Saigon-Dong Nai hydrosystems.

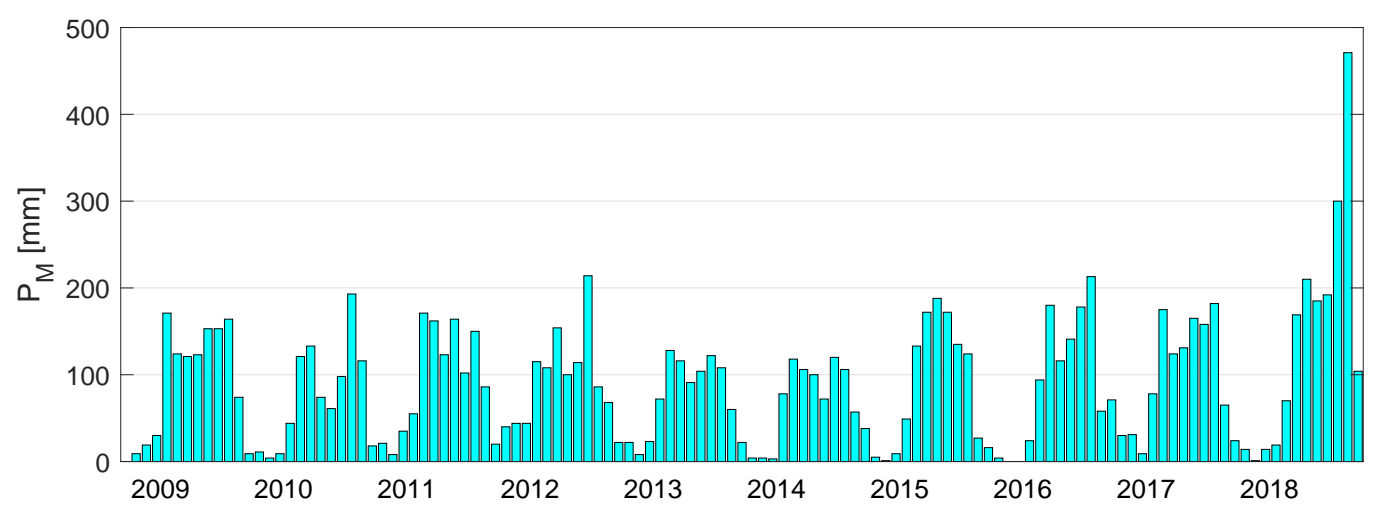

Figure 10: Monthly rainfall $P_{M}$ at HCMC from 2009 to 2019.

699 2017-2018 and 2018-2019 hydrological seasons that are reported in Figure 9 support the hypothesis of a phase of recovery after these pluri-annual 
droughts. The 2017 wet season showed a priori an atypical hydrological response, with a normal rainy season from May to October, that is not in correlation with water discharge due to strong exchanges with groundwater. There is indeed a shift between the discharge increase and the precipitation increase. This may result of years of deficit in the groundwater.

In 2018, the precipitation-river interaction was noticeably different. It seems the groundwater recovered from the drought leading to a more typical response of the river to precipitation. We may hypothesize that regional recovery of rain during the last wet seasons (2016-2018) led to a recharge of the groundwater table, and further of the river, presumably because the floodplain had fully recovered from the pluri-annual drought that hit the region from 2013 to 2016.

\subsection{Effects of an extreme event: the Usagi typhoon}

On November 25th 2018, HCMC was hit by Usagi typhoon. Arriving from the East-south east, it reached the coast, at $50 \mathrm{~km}$ of Ho Chi Minh City (Ba Ria-Vung Tau Province) in the morning. It continued moving Northwest ward inland over HCMC area as a tropical depression. According to the forecast department of the Southern Centre for Hydro-Meteorological Forecasting (SCHMF), this was the highest ever recorded rainfall in a 24-hours period in the megalopolis. Districts of HCMC recorder cumulated daily rain 
between 293 to $408 \mathrm{~mm}$ for independent stations of measurements. While there is no debate concerning the intensity of Usagi event and the severity of damages, there is a clear interest in understanding how the hydrosystem physically behaved during and just after those exceptional rains. The paradoxical result is the lack of direct response of the Saigon River to the extreme precipitations. As shown in Figure 5, none of the two hydrological stations recorded any consistent rise of the water level during the typhoon, neither any flash rise of the river discharge (Figure 6). The only noticeable impact recorded by our CTD sensors was a slight reduction of the conductivity at the PC station, which dropped of a few percent when Usagi typhoon hit the region (not shown in this paper). Could we conclude that the typhoon had no effects on the river dynamics? Has the Dau Tieng dam totally regulated the flow?

By comparing data from November 2017 and November 2018, one can observe that despite a rise of rainfall by a factor six, mean water level and net discharge reduced during this period by 15\% (0.77 m in Nov. 2017 and $0.66 \mathrm{~m}$ in Nov. 2018) and $50 \%\left(65 \mathrm{~m}^{3} / \mathrm{s}\right.$ in Nov. 2017 and $30 \mathrm{~m}^{3} / \mathrm{s}$ in Nov. 2018), respectively. It clearly shows that floods observed in some districts of the city during the event were not directly driven by the overflow of water from the river, but certainly by intense run off over impervious streets (Figure ??). Also, we should not underestimate the potential impact of the Dau Tieng 
dam management; large amount of water may have been retained during the flood and slowly reinjected in the river during the following weeks. Finally, since tide-average water levels in the Saigon River are relatively higher in late fall (Fig. 9), and because of the storm surge, evacuation of water may have been more difficult. This can be explained by the morphology of the delta, which is very flat and close to the sea shore. Results from Scussolini et al. (2017) showed the influence of the sea level on HCMC flood risk. Ho et al. (2014) argued that main hydrological explanations for the flood risk on HCMC area are the upstream floods including those of the Dong Nai and Mekong delta, local rainfall, land subsidence, and sea level rise. Our results indicate that local rainfall and sea water level may be the most impacting factors.

\section{Conclusion}

Tidal rivers and their floodplains are environments that are hardly monitored although they concentrate most of the human activities and form habitats for rich ecosystems. Flood risk is a particular issue for such environment and requires a good monitoring and a good understanding of its hydrological functioning.

Here, we applied a stage-fall-discharge rating curve adapted from the general Manning-Strickler law (Camenen et al., 2017) to assess the instantaneous 
water discharge on the Saigon River. For the first time, the Saigon River dynamics was recorded at high frequency over two hydrological years, including the heaviest rain event ever recorded. Such tool appears to be a very efficient and low cost system for estimating discharge in tidal rivers as soon as the tidal wave is not too asymmetric and the river bed is stable (no general erosion nor aggradation). One issue remains the estimation of the slope since the model is sensitive to possible errors in water level measurements. This is particularly true for the Saigon River, which is tide dominated.

The analysis of the data-series highlights the driving role of tides on water mixing and water dynamics at hourly to monthly timescales. Once filtered from tidal effects, the averaged water level and water discharge points out a rather small contribution of run-off and a potential significant impact of flood plain and anthopogenic structures (Dau Tieng dam, canals, water pumping, etc.) to the hydrosystem response. The study of river response during Usagi typhoon illustrated how much the floodplain can attenuate the direct impact of intense precipitations and how critical is the sea water level to evacuate the flood. Also, the seasonal variability of the tidal-averaged water levels showed a possible influence of the nearby Mekong high flows that reduces the slope and limits the net discharge.

This study remains a preliminary study, which needs to be completed with some further studies on groundwater and flood plain dynamics, including 


\section{References}

Camenen, B., Dramais, G., Le Coz, J., Ho, T.-D., Gratiot, N., and Piney, S. (2017). Estimation d'une courbe de tarage hauteur-dénivelée-débit pour une rivière influencée par la marée. La Houille Blanche, 5:16-21. (in French). 
Chen, C., Lai, Z., Beardsley, R. C., Xu, Q., Lin, H., and Viet, N. T. (2012a). Current separation and upwelling over the southeast shelf of Vietnam in the South China Sea. Journal of Geophysical Research, 117(C03033):1-16.

Chen, Y.-C., Yang, T.-M., Hsu, N.-S., and Kuo, T.-M. (2012b). Real-time discharge measurement in tidal streams by an index velocity. Environmental Monitoring \& Assessment, 184:6423-6436.

Dinehart, R. L. and Burau, J. R. (2005). Repeated surveys by acoustic Doppler current profiler for flow and sediment dynamics in a tidal river. Journal of Hydrology, 314(1-4):1-21.

Ho, L. P., Nguyen, T., Chau, N. X. Q., and Nguyen, K. D. (2014). Integrated urban flood risk management approach in contextof uncertainties: case study Ho Chi Minh city. La Houille Blanche, 6:26-33.

Hoitink, A. J. F., Buschman, F. A., and Vermeulen, B. (2009). Continuous measurements of discharge from a horizontal acoustic Doppler current profiler in a tidal river. Water Resources Research, 45(11 ( W1140)):1-13.

Le Coz, J., Blanquart, B., Pobanz, K., Dramais, G., Pierrefeu, G., Hauet, A., and Despax, A. (2016). Estimating the uncertainty of streamgauging techniques using in situ collaborative interlaboratory experiments. Journal of Hydraulic Engineering, 509:573-587. 
Mansanarez, V., Le Coz, J., Renard, B., Lang, M., Pierrefeu, G., and Vauchel, P. (2016). Bayesian analysis of stage-fall-discharge rating curves and their uncertainties. Water Resources Research, 52:7424-7443.

Mao, Q., Shi, P., Yin, K., Gan, J., and Qi, Y. (2004). Tides and tidal currents in the Pearl River Estuary. Continental Shelf Res., 24(16):1797-1808.

McGranahan, G., Balk, D., and Anderson, B. (2007). The rising tide: Assessing the risks of climate change and human settlements in low elevationcoastal zones. Environment and Urbanization, 19(1):17-37.

Mei, X., Zhang, M., Dai, Z., Wei, W., and Li, W. (2019). Large addition of freshwater to the tidal reaches of the yangtze(changjiang) river. Estuaries 8 Coasts, 42:629-640.

Nguyen, T. T. N., Némery, J., Gratiot, N., Strady, E., Tran, V. Q., Nguyen, A. T., Aimé, J., and Peyne, A. (2019). Nutrient dynamics and eutrophication assessment in the tropical riversystem of Saigon - Dongnai (southern Vietnam). Science Total Environment, 653:370-383.

Petersen-Øverleir, A. and Reitan, T. (2009). Bayesian analysis of stagefall-discharge models for gauging stations affected by variable backwater. Hydrological Processes, 23(21):3057-3074. 
Rantz, S. E. (1963). An empirical method of determining momentary discharge of tide-affected streams. Water-Supply Paper 1586-D, U. S. Geological Survey, Washington, USA. 33 p.

Rantz, S. E. (1982). Measurement and computation of streamflow: Volume 2. Computation of discharge. Water-Supply Paper 2175, U. S. Geological Survey. 313 p.

Ruhl, C. A. and DeRose, J. B. (2004). Monitoring alternatives at the Sacramento River at Freeport, California: results ofthe 2002-2004 pilot study. Technical Report Scientific Investigation Report 2004-5172, U. S. Geological Survey, Reston, Virginia.

Ruhl, C. A. and Simpson, M. (2006). Computation of discharge using the index-streamflow: method in tidally affected areas. Technical Report Scientific Investigations Report 2005-5004, U. S. Geological Survey, Reston, Virginia.

Sassi, M. G. and Hoitink, A. J. F. (2013). River flow controls on tides and tide-mean water level profiles in a tidal freshwater river. Journal of Geophysical Research, 118:4139-4151.

Sassi, M. G., Hoitink, A. J. F., Vermeulen, B., , and Hidayat (2011). Discharge estimation from $\mathrm{H}-\mathrm{ADCP}$ measurements in a tidal river sub- 
ject to sidewall effects and a mobile bed. Water Resources Research, 47(W06504):1-14.

Scussolini, P., Tran, T. T. V., Koks, E., Diaz-Loaiza, A., Ho, P. L., and Lasage, R. (2017). Adaptation to sea level rise: Amultidisciplinary analysis for ho chiminh city, vietnam. Water Resources Research, 53:10,841-10,857.

Taniguchi, M., Allen, D., and Gurdak, J. (2013). Optimizing the waterenergy-food nexus in the Asia-Pacific Ring of Fire. Eos, Transactions of the American Geophysical Union, 94(47).

Thi Ha, D., Ouillon, S., and Van Vinh, G. (2018). Water and suspended sediment budgets in the Lower Mekong from high-frequency measurements (2009-2016). Water, 10(7, 846):1-24.

Thirumalai, K., DiNezio, P. N., Okumura, Y., and Deser, C. (2017). Extreme temperatures in Southeast Asia caused by El Niño and worsened by global warming. Nature Communications, 8(15531).

Vachaud, G., Quertamp, F., Phan, T. S. H., Tran Ngoc, T. D., Nguyen, T., Luu, X. L., Nguyen, A. T., and Gratiot, N. (2019). Flood-related risks in ho chi minh city and ways of mitigation. Journal of Hydrology, 573:1021-1027. 
Van, T. P. and Koontanakulvong, S. (2018). Groundwater and river interaction parameter estimation in Saigon River, Vietnam. Engineering Journal, 22(1):257-267.

van Driel, W. F., van, Bucx, T., Makaske, A., van de Guchte, C., van der Sluis, T., Biemans, H., Ellen, G. J., van Gent, M., Prinsen, G., and Adriaanse, B. (2015). Vulnerability assessment of deltas in transboundary river basins. techreport Report 9, Delta Alliance International, WageningenDelft, The Netherlands. Delta Alliance contribution to the Transboundary Water Assessment Program, River Basins Assessment.

Van Leeuwen, C. J., Dan, N. P., and Dieperink, C. (2016). The challenges of water governance in Ho Chi Minh City. Integrated Environmental Assessment \& Management, 12(2):345-352.

Zhao, J., Chen, Z., Zhang, H., and Wang, Z. (2016). Multiprofile discharge estimation in the tidal reach of Yangtze Estuary. Journal of Hydraulic Engineering, 142(12, 04016056):1-12.

\section{Appendix A. Sensitivity analysis}

\section{Appendix A.1. Error calculation on experimental data}

A first sensitivity analysis was made to optimize main model parameters (Strickler coefficient $K$ and the time shift $\Delta t$ ) to experimental data. For 
both ADCP campaigns in September 2016 and March 2917 (see Figure 3), the estimation of the error was made using the mean square error :

$$
E(Q)=\sqrt{\frac{1}{n} \sum_{i=1}^{n}\left[Q_{\text {mod. }}\left(t_{i}\right)-Q_{\text {meas. }}\left(t_{i}\right)\right]^{2}}
$$

where $n$ is the number of gauging data, $Q_{\text {mod. }}$ the modelled discharge and $Q_{\text {meas. }}$ the measured discharge, and $t_{i}$ the time of each of these gauging. As can be observed in Fig. A.11, errors are significantly smaller for the first campaign for which the tide was more symmetrical. Indeed, $E(Q) \approx$ $200 \mathrm{~m}^{3} / \mathrm{s}$ for the September 2016 campaign whereas $E(Q) \approx 350 \mathrm{~m}^{3} / \mathrm{s}$ for the March 2017 campaign. From this sensitivity analysis, one would choose $K=25 \mathrm{~m}^{1 / 3} / \mathrm{s}$ and $\Delta t=-2.04 \mathrm{~h}$.

(a)

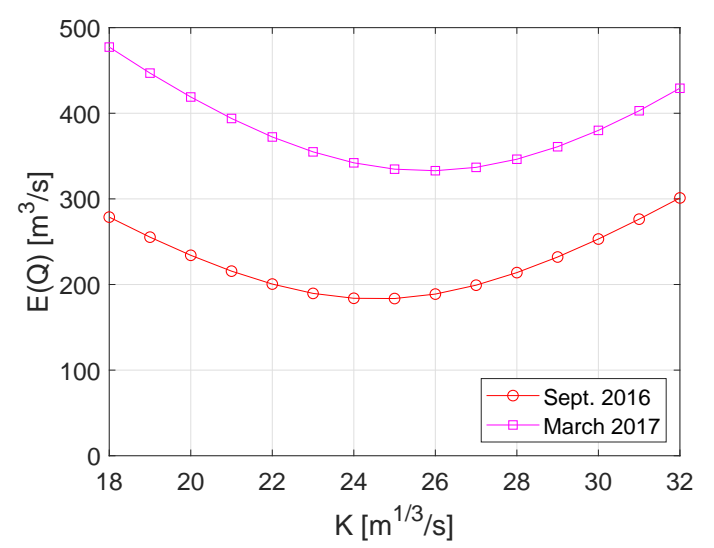

(b)

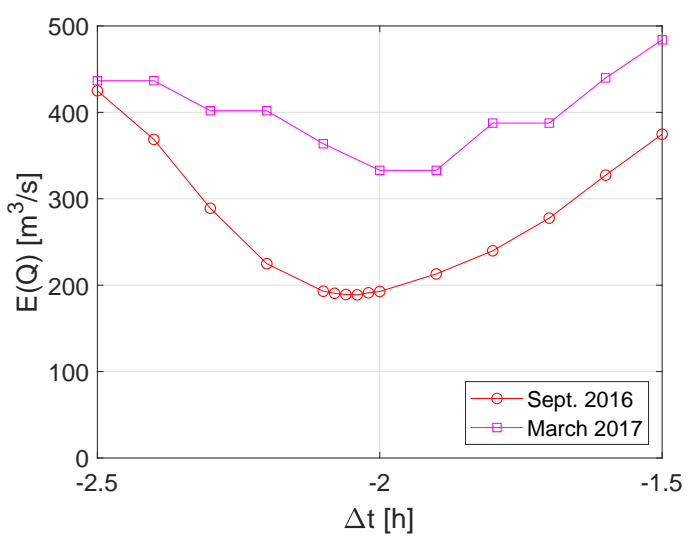

Figure A.11: Sensitivity of the Strickler coefficient $K$ (a) and time shift $\Delta t$ (b) on the error calculation compared to ADCP campaigns.

However, as can be seen in Figure A.12a, using $K=25 \mathrm{~m}^{1 / 3} / \mathrm{s}$ would 
lead to some underestimation of the peak discharge values. Indeed, the error calculation is biased by the more numerous data points around the zero discharge value, which are slightly better predicted using a smaller value of the Strickler coefficient (see also Figure 3). Also, the effect of $\Delta t$ appears not as sensitive. It is also important to realize that water level data present a frequency of $10 \mathrm{~min}$ (1 min in September 2016), which does not allow to fit $\Delta t$ in such detail. Moreover, the position of the Thao Dien station (used for the 2017-2018 period) being a few km upstream of Bach Dang (used during the September 2016 experiment, see Figure reffig:Saigon), the time shift should be smaller. As a consequence, we eventually chose $K=26 \mathrm{~m}^{1 / 3} / \mathrm{s}$ and $\Delta t=-2.0 \mathrm{~h}$.

(a)

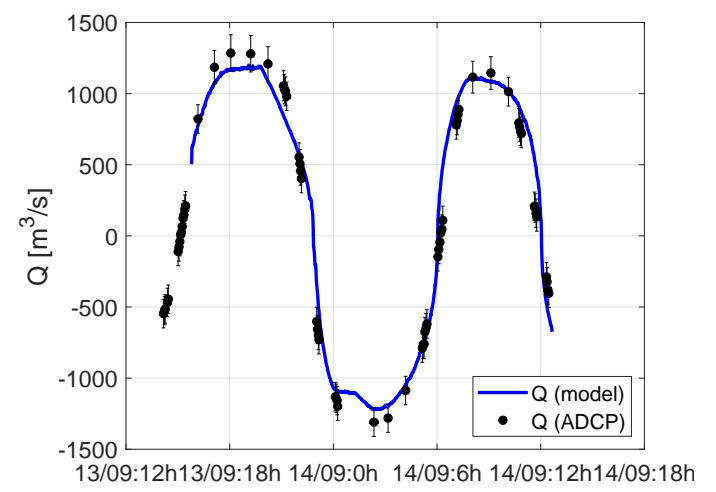

(b)

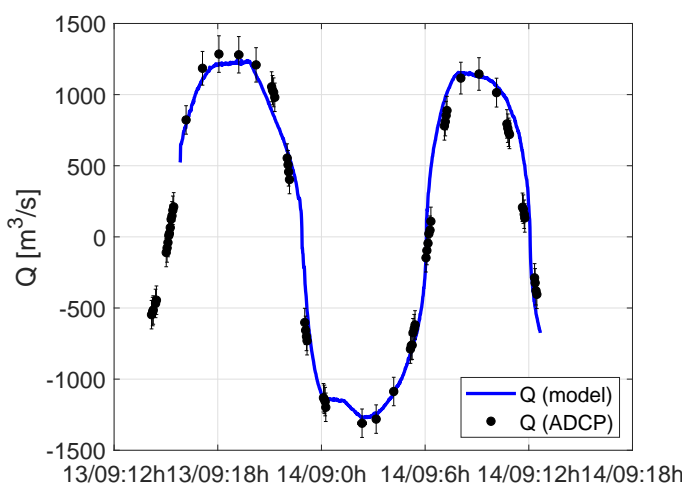

Figure A.12: Comparison between the model and discharge measurement campaigns in September 2016 using $K=25 \mathrm{~m}^{1 / 3} / \mathrm{s}$ and $\Delta t=-2.00 \mathrm{~h}$ (a) and $K=26 \mathrm{~m}^{1 / 3} / \mathrm{s}$ and $\Delta t=-2.04 \mathrm{~h}(\mathrm{~b})$. 


\section{Appendix A.2. Sensitivity analysis on main parameters}

Equation (2) was calibrated by fitting two parameters: the Strickler coefficient $K$ and the time shift $\Delta t$. As can be observed in Figure A.13, the Strickler coefficient has a linear effect on both instantaneous and net discharge. It is quite obvious since $Q \propto K$. An error of approximately $8 \%$ in $K$ would yield an error of $8 \%$ as well for both instantaneous and net discharge.

(a)

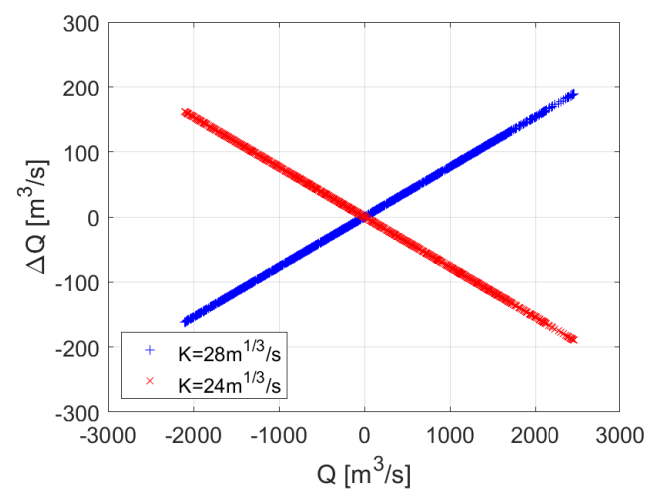

(b)

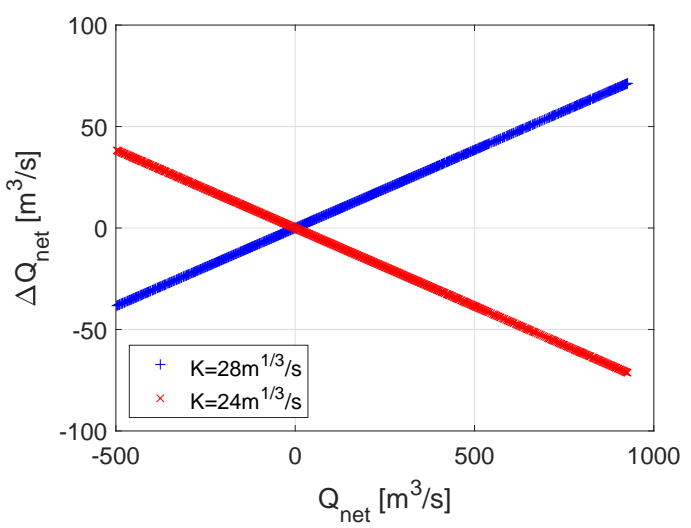

Figure A.13: Sensitivity of the Strickler coefficient $K$ on the instantaneous (a) and net (b) discharge.

Since the coefficient $\Delta t$ leads to a time shift of the curves, it induces large errors around the flow reverse (Figure A.14). However, the effect on the net discharge is very low; a shift of 12 min leads to an error of $\pm 5 \mathrm{~m}^{3} / \mathrm{s}$ approximately. 
(a)

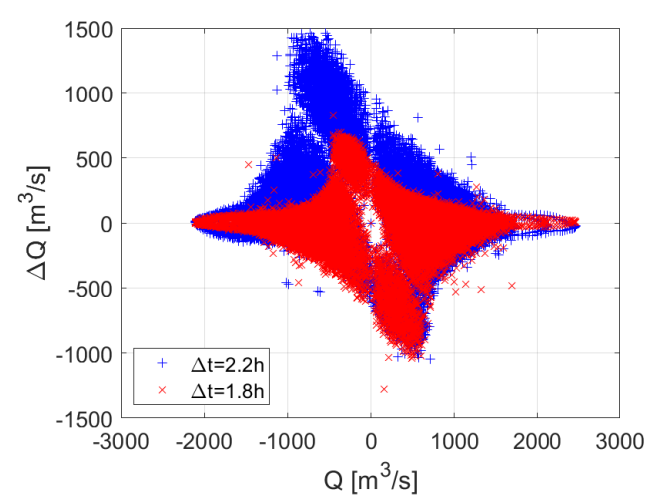

(b)

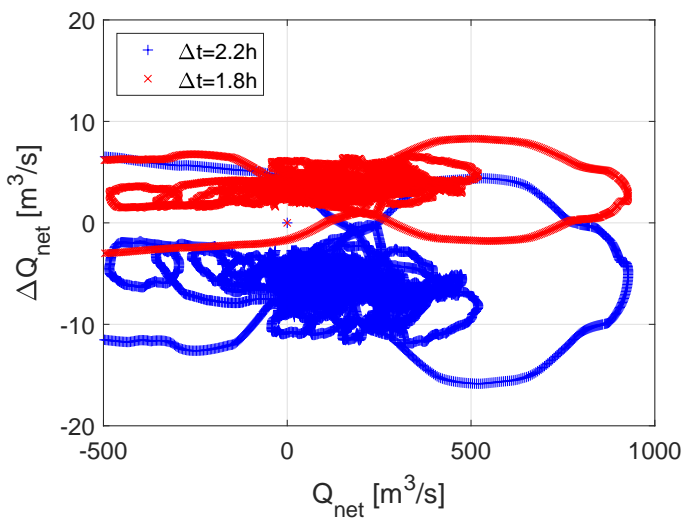

Figure A.14: Sensitivity of the time shift $\Delta t$ on the instantaneous (a) and net (b) discharge.

Appendix A.3. Sensitivity analysis on input

The only input data of the model (Equation (2)) are the water levels measured at the downstream and upstream stations. The water level measured downstream will only affect the slope estimation whereas the water level upstream (at the reference station PC) will also affect the estimation of the wet section and hydraulic radius.

In Figure A.15 is tested an error of $1 \mathrm{~cm}$ in the downstream water level on the estimated discharge. The effect is inversely proportional to the discharge and errors can reach $300 \mathrm{~m}^{3} / \mathrm{s}$ for $Q(t) \approx 0$ assuming an error of $1 \mathrm{~cm}$. The asymmetrical shape of the figure is due the the time shift on the slope. On the other hand, error on the net discharge is quite limited but not negligible with an error of $\pm 20 \mathrm{~m}^{3} / \mathrm{s}$ approximately. 
(a)

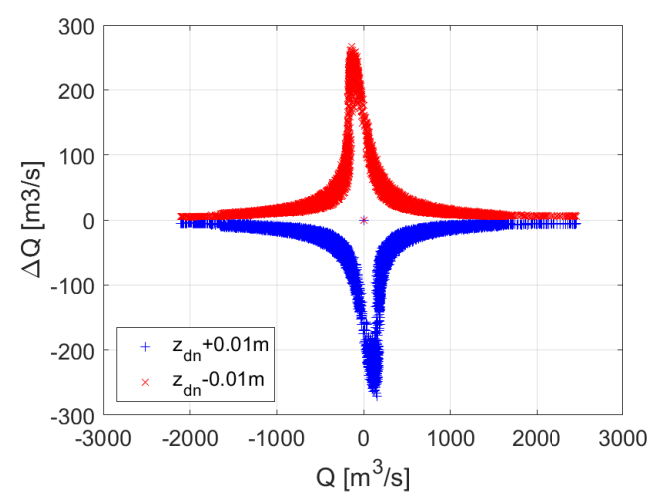

(b)

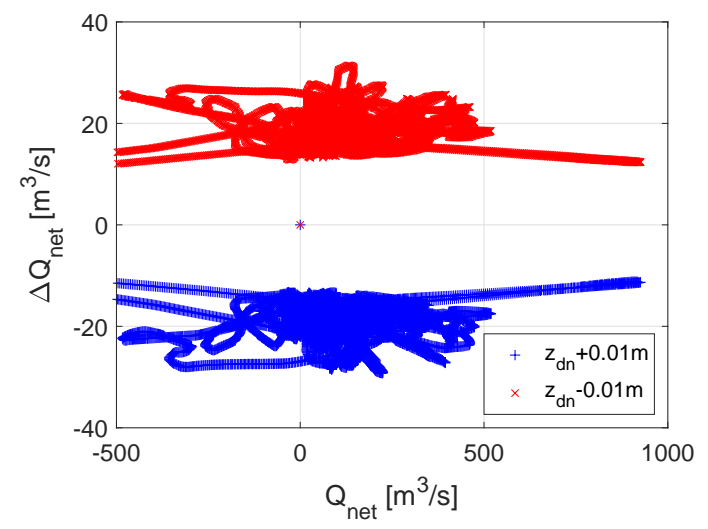

Figure A.15: Sensitivity of the water level measured downstream on the instantaneous (a) and net (b) discharge.

In Figure A.16 is presented the errors in discharge estimations for an error of $1 \mathrm{~cm}$ in the upstream water level. Surprisingly, effects are very similar (opposite) to the error in the downstream water level. Indeed, the sensitivity on the water slope is much higher than the sensitivity on the hydraulic radius or wet section. 
(a)

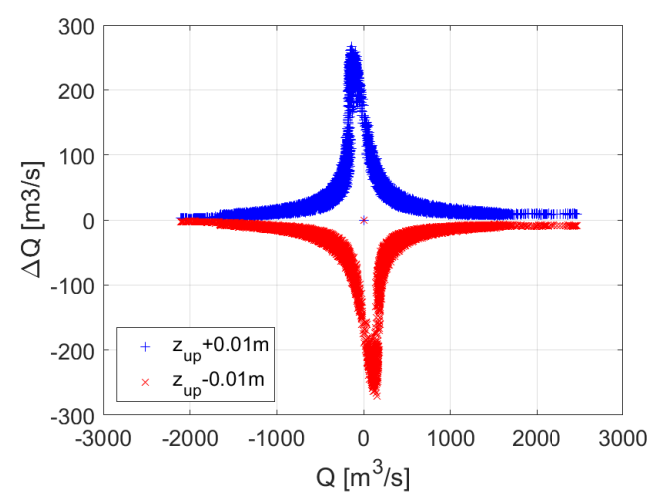

(b)

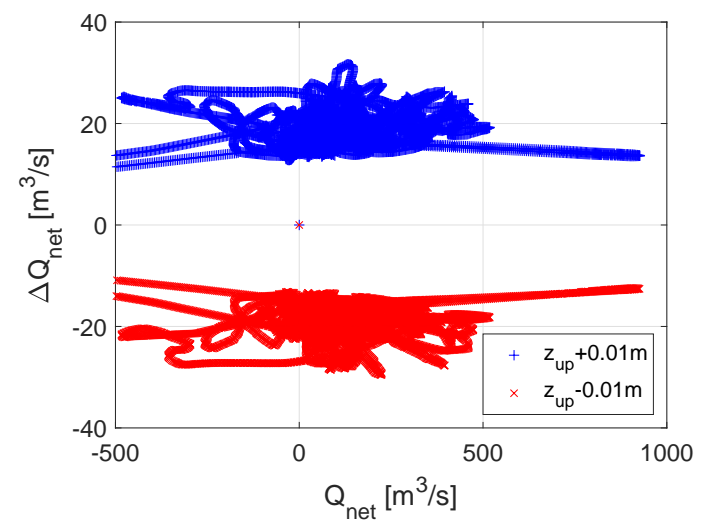

Figure A.16: Sensitivity of the water level measured upstream on the instantaneous

(a) and net (b) discharge. 